\title{
Termination of pregnancy for fetal anomaly in a Tunisian population
}

\author{
E B Hamida, ${ }^{1} \mathrm{MD}$; I Ayadi, ${ }^{1} \mathrm{MD}$; A Bezzine, ${ }^{1} \mathrm{MD}$; B Rabii, ${ }^{1} \mathrm{MD}$; S B Hammouda, ${ }^{2} \mathrm{MD}$; B Bouguerra,${ }^{2} \mathrm{MD}$; \\ Z Marrakchi, ${ }^{1} \mathrm{MD}$ \\ ${ }^{1}$ Department of Neonatology, Charles Nicolle Hospital, Faculty of Medicine of Tunis, Tunis El Manar University, Tunisia \\ ${ }^{2}$ Department of Obstetrics and Gynaecology, Charles Nicolle Hospital, Faculty of Medicine of Tunis, Tunis El Manar University, Tunis, Tunisia
}

Corresponding author: E B Hamida (emira@ben-hamida.com)

\begin{abstract}
Background. Progress in prenatal diagnosis and prenatal screening in the past 2 decades has facilitated improved diagnostic methods for fetal abnormalities.

Objectives. To assess the indications for late termination of pregnancy, gestational ages and to discuss ethical and legal considerations.

Methods. A retrospective study compiling and analysing data from justified medical terminations of pregnancies, reported between January 2001 and June 2012 at Charles Nicolle Hospital. Congenital infectious embryofetopathies were excluded.

Results. Over this period, there were 77 cases of clinically justified medical terminations of pregnancies - a rate of 1.9 per 1000 total births. The mean gestational age was 27 weeks. In 33 cases, the medical abortion was performed beyond 26 weeks (42.8\%). Fetal malformations were predominantly of the central nervous system.

Conclusion. Medical terminations of pregnancy for fetal indications are relatively rare. However, they raise ethical, medical and legal issues, due in part to a late prenatal diagnosis. Such decisions should be taken through a multidisciplinary committee.
\end{abstract}

S Afr J Obstet Gynaecol 2017;23(2):69-70. DOI:10.7196/SAJOG.2017.v23i2.1159

Advances in prenatal diagnosis allow the screening of various fetal malformations during pregnancy. In the absence of therapeutic options, the possibility of termination of pregnancy (TOP) for fetal anomaly is more and more likely to be considered. This raises many religious, social, and ethical questions. ${ }^{[1-3]}$ Since 1973, Tunisian law has permitted TOP under two circumstances: voluntary and elective. Abortion is permissible prior to 12 weeks of gestation in cases of unwanted pregnancy. Pregnancy may be terminated at any period of gestation if there is a serious maternal health problem, including psychological conditions and/or fetal conditions with a high risk of severe disability or fatality. Approval for elective TOP can be given by one physician who declares that there is a maternal or fetal reason justifying the TOP. There is no upper gestation limit to late TOP stated in Tunisian legislation. ${ }^{[4,5]}$ The aim of our study was to assess the indications of late TOP, gestational ages and to discuss ethical and legal considerations.

\section{Methods}

This was a retrospective study conducted between January 2001 and June 2012 at the Department of Neonatology at Charles Nicolle Hospital (CNH) of Tunis, Tunisia, which is a referral centre for high-risk pregnancies. There are 3000 - 4000 births every year at $\mathrm{CNH}$ from an average of 170000 annual births in Tunisia.

Inclusion criteria were all births from a TOP at 22 or more weeks of gestation or weighing $\geq 500 \mathrm{~g}$ when gestational age was unknown. Births from medical terminations of pregnancy owing to congenital infectious embryofoetopathies were excluded.

Data were obtained from the clinical records of the mother and the neonate. The data were recorded and analysed using Epi Info 6.04d for DOS (Centers for Disease Control and Prevention, USA). Descriptive parameters are presented as mean (SD) and frequencies are presented as percentages.

\section{Results}

Over the 11-year period there were 77 cases of TOP for fetal anomalies among 39943 total births, giving a rate of 1.9 per 1000 births. Forty-four cases (62.3\%) were stillbirths.

Indications for TOPs owing to fetal anomalies are summarised in Fig. 1. Central nervous system defects represented 53\% of all indications, followed by chromosomal anomalies (21\%). Anencephaly and spina bifida were responsible for $33.7 \%$ of all TOPs. Chromosomal anomalies included 10 cases of trisomy 21 (62.5\%), 2 cases of trisomy 18 (12.5\%), 3 cases of trisomy 13 (18.7\%) and 1 case of a deletion of the short arm of chromosome 18. All fetal anomalies were suspected by antenatal ultrasound, except for a case of $\beta$-thalassaemia major. The first antenatal ultrasound was performed in the first trimester in 37 mothers (48\%), in the second trimester in 26 mothers $(33.7 \%)$ and in the third trimester in 14 mothers (18.1\%).

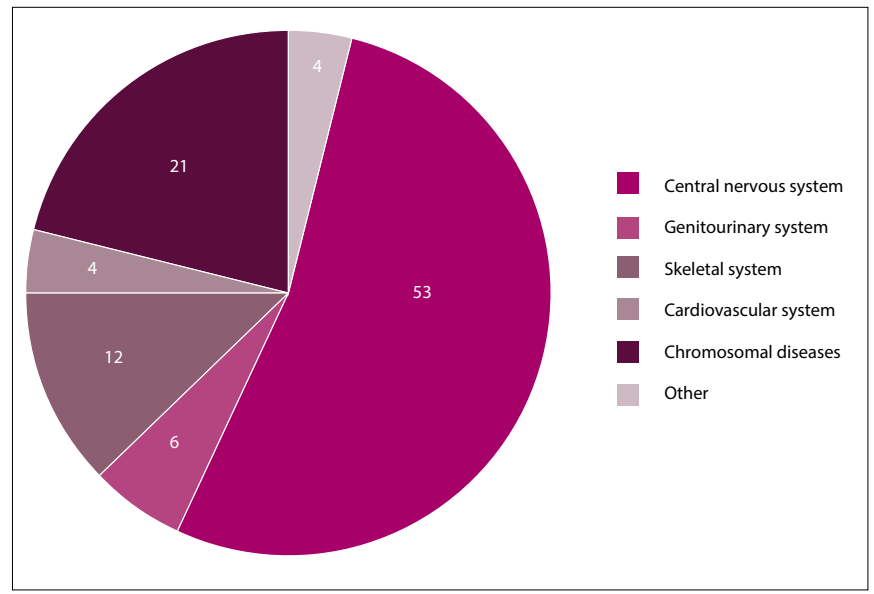

Fig. 1. Indications for termination of pregnancy (\%). 
Fetal anomalies were detected at a mean (SD) gestational age of 24 (3.2) weeks. No cases were suspected in the first trimester, 58 cases (75.3\%) were recognised between 18 and 26 weeks, and 19 cases (24.6\%) between 26 and 36 weeks.

The mean (SD) gestational age at termination was 27 (3.5), (range 22 - 36) weeks. In 33 cases (42.8\%), TOP was performed beyond 26 weeks and 15/33 (45.4\%) were born alive. Among the infants born alive beyond 26 weeks, 10/15 (66.6\%) died within the first hours after birth, 2 died between 2 and 7 days, one at day 17, and 2 at day 23. The 2 latter patients died after discharge: 1 neonate, born at 26 weeks, had Down's syndrome, and the other, born at 30 weeks, had hydrocephaly. No neonatal intensive care was offered to the newborns.

\section{Discussion}

Our study demonstrated a majority of central nervous system defects as indications of TOP for fetal anomaly. This pattern was consistent with previous studies. ${ }^{[1]}$ Chromosomal abnormalities were the second most common indication for TOP, and trisomy 21 was the most common chromosomal abnormality as found by other studies.

In our practice there is a lack of consensus around which abnormalities are severe enough to indicate termination, and up to what gestational age TOP is acceptable. The law allows TOP for fetal abnormality after the first trimester if the abnormality is 'serious', but there is a wide variation in the views of practitioners. Some obstetricians regard a cleft palate as a major abnormality, while some believe that TOP should be considered for only lethal conditions such as anencephaly and trisomy 18. Late TOP for achondroplasia, hydrocephaly or Down's syndrome could not be justified since they are viable abnormalities, but not lethal. ${ }^{[3]}$

If the anomaly is not lethal, the paediatrician may be confronted by a difficult dilemma if the fetus is born alive and requires resuscitation or intensive care. In Tunisia, viability is considered common beyond 26 weeks. From there, the fetus is regarded as a patient who is entitled to the legal protection available to any other child.
Paediatricians may encounter legal problems if they decide not to resuscitate the newborn. In our study, TOP was performed beyond 26 weeks in more than $45 \%$ of cases. Two infants were even discharged before dying a few days later.

Thus, before deciding on the means of terminating the pregnancy, it is important to define whether the fetus will be born alive, in which case feticide would have to be discussed. Without feticide, an infant may be born alive; however, the majority of obstetricians refuse to practise it for religious reasons. In such situations, TOP should be undertaken after careful discussion between attending obstetric and neonatal staff, and the woman and her family, with all parties agreeing to a written care plan before the termination takes place.

\section{Conclusion}

Medical TOPs for fetal indications are relatively rare. However, they raise ethical, medical and legal issues, due in part to a late prenatal diagnosis. Such decisions should be taken through a multidisciplinary committee containing at least an obstetrician, neonatologist and a geneticist.

Acknowledgement. All authors.

Author contributions: All authors contributed equally to the work presented in this paper.

Funding. None.

Conflicts of interest. None.

\footnotetext{
1. Aslan H, Yildirim G, Ongutb C, Ceylan Y. Termination of pregnancy for fetal anomaly. Int Gynecol Obstet 2007;99:221-224. https//doi.org/10.1016/j.ijgo.2007.05.047

2. Gitsels-van der Wal JT, Manniën J, Ghaly MM, Verhoeven PS, Hutton EK, Reinders HS. The

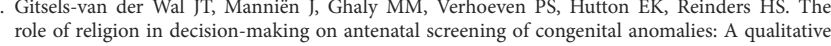
study amongst Muslim Turkish origin immigrants. Midwifery 2014;30:297-302. https://doi. org/10.1016/j.midw.2013.04.001

3. Statham H, Solomou W, Green J. Late termination of pregnancy: Law, policy and decision-making in four English fetal medicine units. BJOG 2006;113:1402-1411. https://doi.org/10.1111/j.1471 0528.2006.01144.x

4. Décret-Loi $n^{\circ} 73-2$ du 26 Septembre 1973 portant modification de l'article 214 du code pénal. http://legislation-securite.tn/node (accessed 21 August 2017).

5. Blum J, Hajri S, Chelli H, Ben Mansour F, Gueddana N, Winikoff B. The medical abortion experiences of married and unmarried women in Tunis, Tunisia. Contraception 2004;69:63-69.
} https://doi.org/10.1016/j.contraception.2003.08.019 